\title{
TRANSMISIÓN VERTICAL DE HTLV-1 EN EL PERÚ
}

\author{
Jorge Alarcón Villaverde 1,2,a, Franco Romaní Romaní 2,b, Silvia Montano Torres 3,c, \\ Joseph R. Zunt ${ }^{4, c}$
}

\begin{abstract}
RESUMEN
La infección por el virus linfotrópico humano de células T tipo 1 (HTLV-1) ha sido descrita en muchas áreas del mundo, como en los países del Caribe, Japón, África, Oceanía y en Sudamérica. En la presente revisión definimos la endemicidad del HTLV-1 en el país, planteando cuatro criterios epidemiológicos. Luego discutimos el tema central de la revisión: la transmisión vertical del HTLV-1, que en nuestro país sería uno de los principales mecanismos de transmisión. Dentro del desarrollo de este aspecto en particular, presentamos una estimación de la tasa de transmisión vertical y los factores de riesgo asociados con la transmisión vertical sobre la base de una revisión exhaustiva de estudios nacionales y extranjeros. Con esta revisión pretendemos dar una primera aproximación al estudio de la trasmisión vertical de HTLV-1, un aspecto poco estudiado en nuestro medio.
\end{abstract}

Palabras clave: Virus Linfotrópico T Humano Tipo 1; HTLV-1; Transmisión Vertical; Perú (fuente: DeCS BIREME).

\section{VERTICAL TRANSMISSION OF HTLV-1 IN PERU}

\begin{abstract}
Human type 1 T-cell lymphotropic virus (HTLV-1) infection has been described in many areas of the world, including Caribbean countries, Japan, Africa, Oceania and South America. In this review we define the endemicity of HTLV-1 in the country proposing four epidemiological criteria. Then we discuss the core subject of the review, which is the vertical transmission of HTLV-1. This mechanism is one of the main forms of transmission in our country. Within the development of this particular topic, we present an estimated rate of vertical transmission and the risk factors associated to vertical transmission based on an exhaustive review of the national and international literature. This review pretends to provide a first approach to the vertical transmission of HTLV-1, an aspect poorly studied in our country.
\end{abstract}

Keys words: Human T-Lymphotropic Virus 1 (HTLV-1); Vertical Transmission; Peru (source: MeSH NLM).

\section{INTRODUCCIÓN}

El virus linfotrópico humano de células T (HTLV-1) ha sido ampliamente estudiado. A pesar de ello, aún no se tiene una cifra aproximada del número de individuos infectados en el mundo, pues la mayoría de datos de prevalencia provienen de estudios realizados en donantes de sangre de bajo riesgo o en grupos de población seleccionados (gestantes, pacientes con enfermedades neurológicas o hematológicas, grupos nativos, usuarios de drogas endovenosas, trabajadores sexuales y homosexuales), no representativos de la población general (1-4). No obstante esta limitación, un estudio del año 1996 estimó que en el mundo hay entre 15 a 20 millones de personas que viven con esta infección (1), con variaciones geográficas dependientes de la composición demográfica y de los comportamientos de riesgo ${ }^{(1,2)}$.
En América del sur, que tiene cerca de 350 millones de habitantes en 13 países, la infección por HTLV-1 ha sido reportada en la mayoría de ellos. En el año 2002 en países del Caribe (Centro América) como Jamaica y Trinidad, la prevalencia fue de $5 \%$ en la población general ${ }^{(2)}$. En el Perú, la prevalencia de la infección entre donantes de sangre, gestantes y trabajadoras sexuales en varias partes del país varía de 1 a $7 \%{ }^{(5-14)}$.

En áreas endémicas la infección por HTLV-1 tiende a presentarse en grupos familiares y vecinos, característica que se asocia con la transmisión vertical. Sin embargo, se ha observado que en generaciones subsecuentes de personas que migran de un área endémica hacia áreas no endémicas, la prevalencia tiende a disminuir ${ }^{(1,15)}$, lo que sugiere que, además de la trasmisión vertical existen cofactores biológicos y sociales que influyen en la trasmisión de HTLV-1 ${ }^{(1)}$. Un factor importante de la

\footnotetext{
Departamento Académico de Medicina Preventiva y Salud Pública, Facultad de Medicina, Universidad Nacional Mayor de San Marcos. Lima, Perú.

2 Sección de Epidemiología, Instituto de Medicina Tropical, Facultad de Medicina, Universidad Nacional Mayor de San Marcos. Lima, Perú.

3 Centro de Investigación de Enfermedades Tropicales de la Marina de los EEUU (NAMRU-6), Perú.

4 Departamentos de Medicina, Salud Global y Neurología. Escuela de Medicina. Universidad de Washington (Seattle).

a Médico, MPH, Doctor en medicina; ${ }^{\mathrm{b}}$ Médico Cirujano; ${ }^{\mathrm{c}}$ Médico Neurólogo, MPH.
} 
transmisión vertical es la lactancia materna ${ }^{(5,9)}$; pero ha sido poco estudiada en nuestro medio.

La presente revisión tuvo como objetivo mostrar el carácter endémico de HTLV-1 en el Perú, estimar la tasa de transmisión vertical, identificar los factores de riesgo de transmisión vertical y comparar estos aspectos con otros países endémicos.

\section{MATERIALES Y MÉTODOS}

Se realizó una búsqueda bibliográfica exhaustiva en las bases de datos PubMed y LILACS en junio del año 2009; para este fin se usó como palabras clave "Transmisión vertical", "HTLV-1", "HTLV-1 en gestantes" y "Perú". Se seleccionaron artículos relacionados con los siguientes temas: prevalencia de HTLV-1 en gestantes, epidemiología de HTLV-1 y estudios de transmisión vertical de HTLV-1.

\section{ENDEMICIDAD EN EL PERÚ}

El carácter endémico de la infección por HTLV-1 en el Perú, se infiere a partir de la presencia de las siguientes características epidemiológicas descritas en la literatura:

- Prevalencia mayor del $1 \%$ en grupos de la población general;

- Prevalencia elevada en grupos expuestos a infecciones de trasmisión sexual;

- Incremento de la prevalencia con la edad;

- Prevalencia en población emigrante.

\section{PREVALENCIA DE HTLV-1}

Proietti et al. proponen que países con prevalencia de 1 a $5 \%$ en algunas poblaciones deben ser considerados endémicos ${ }^{(1)}$, Gotuzzo et al. sugieren que un área sería endémica si la prevalencia de HTLV-1 en población general adulta sana está entre 2 y $10 \%{ }^{(14)}$. De acuerdo con estos autores, el Perú es un área endémica de HTLV-1, dado que la prevalencia entre donantes de sangre, gestantes, trabajadoras sexuales, homosexuales varones y varones privados de libertad en varias partes del país se encuentra entre 1 a $7 \%^{(5-16,17)}$.

Los estudios de prevalencia de HTLV-1 en el Perú han sido realizados en grupos seleccionados y en muestras no representativas de la población general. En todos los estudios publicados $(5,-13,17,18)$, excepto dos $(16,17)$, la prevalencia encontrada ha sido mayor al $1 \%$. Uno de ellos, realizado en 370 pobladores quechuas voluntarios residentes en Cusco y Quillabamba, encontró una prevalencia total del 5,1\%; en este estudio la prevalencia en gestantes sanas es de 2,3\% (5 de 211 gestantes) ${ }^{(5)}$. Otro, en 568 mujeres sanas de más de 20 años en tres regiones del Perú, encontró una prevalencia general del 2,5\%, correspondiendo 1,3\% a Huanta (Ayacucho) 3,8\% a El Carmen (Ica) y 3,8\% a Lima. ${ }^{(9)}$ Los dos estudios en que la prevalencia fue menor de $1 \%$ fueron realizados en donantes de sangre de Arequipa $(0,9 \%)^{(16)}$ y de Puente Piedra, distrito periférico de Lima $(0,75 \%)^{(17)}$.

Los estudios de prevalencia en gestantes podrían dar una mejor idea de la prevalencia en la población general. (1,19). En el caso del Perú se han realizados tres estudios en gestantes residentes en Lima, Huamanga (Ayacucho), Quillabamba y Cusco (Tabla 1). La menor prevalencia se observó en Huamanga (0,5\%); en las otras ciudades la prevalencia fue superior a $1 \%$. El estudio de Lima, realizado en un centro de referencia nacional, fue el que tuvo mayor muestra ${ }^{(8)}$.

De otro lado, estos valores son próximos a los referidos por estudios realizados en países considerados endémicos, como Japón, países del Caribe y África (Tabla 2).

Un hecho que debe destacarse es que en los estudios nacionales se observan diferencias entre las prevalencias encontradas en gestantes y donantes. Esta diferencia también ha sido reportada en otros lugares, como Europa ${ }^{(28)}$, Brasil (23) y Argentina (19); donde Taylor et al., Ribeiro et al. y Trenchi et al. (19) reportan que la prevalencia es seis, cuatro y diez veces mayor en gestantes que en donantes respectivamente. En el caso del Perú, se puede estimar que la razón de la prevalencia de gestantes con la de donantes es de $2,3^{(8,17)}$. Una explicación

Tabla 1. Prevalencia de infección por HTLV-1 en gestantes en el Perú.

\begin{tabular}{|c|c|c|c|c|c|}
\hline Población & $\begin{array}{l}\text { Tamaño } \\
\text { muestral }\end{array}$ & Prevalencia & Año & Observación & Referencia \\
\hline Gestantes de Lima & 2492 & $\begin{array}{c}1,7 \% \\
(H T L V-1)\end{array}$ & 1996-1997 & $\begin{array}{l}\text { Estudio transversal en } 2492 \\
\text { gestantes }\end{array}$ & 8 \\
\hline $\begin{array}{l}\text { Gestantes de Huamanga } \\
\text { (Ayacucho) }\end{array}$ & 602 & $\begin{array}{c}0,5 \% \\
(H T L V-1)\end{array}$ & $2002-2003$ & $\begin{array}{l}\text { Estudio transversal en } 602 \\
\text { gestantes en ciudad del trapecio } \\
\text { andino }\end{array}$ & 6 \\
\hline $\begin{array}{l}\text { Gestantes de } \\
\text { Quillabamba y Cusco } \\
\text { (Cusco) }\end{array}$ & 211 & $\begin{array}{c}2,3 \% \\
(H T L V-1)\end{array}$ & 1996 & $\begin{array}{l}\text { Estudio transversal en } 211 \\
\text { gestantes en ciudad del trapecio } \\
\text { andino }\end{array}$ & 5 \\
\hline
\end{tabular}


Tabla 2: Prevalencia de HTLV-1 en gestantes

\begin{tabular}{|c|c|c|c|c|c|}
\hline País & Prevalencia & Año & Población & Observación & Referencia \\
\hline Argentina & $\begin{array}{c}0,19 \% \\
(H T L V-1 / 2)\end{array}$ & 2000 & Gestantes de Córdova & $\begin{array}{l}\text { Estudio retrospectivo en } 3143 \\
\text { gestantes }\end{array}$ & 19 \\
\hline España & $\begin{array}{c}0,064 \% \\
(\mathrm{HTLV}-1 / 2)\end{array}$ & $\begin{array}{l}1996- \\
1999\end{array}$ & Gestantes de 12 ciudades españolas & $\begin{array}{l}\text { Estudio transversal en } 20366 \\
\text { gestantes }\end{array}$ & 20 \\
\hline Brasil & $\begin{array}{c}0,24 \% \\
(H T L V-1 / 2)\end{array}$ & 2006 & $\begin{array}{l}\text { Puérperas de ciudad de Cuiabá, Mato } \\
\text { Grosso. }\end{array}$ & $\begin{array}{l}\text { Estudio transversal en } 2965 \\
\text { puérperas }\end{array}$ & 21 \\
\hline Brasil & $\begin{array}{c}0,1 \% \\
(\mathrm{HTLV}-1 / 2)\end{array}$ & $\begin{array}{l}2002- \\
2003\end{array}$ & Gestantes del estado de Mato Grosso & $\begin{array}{l}\text { Estudio transversal en } \\
32512 \text { gestantes }\end{array}$ & 22 \\
\hline Brasil & $\begin{array}{c}0,076 \% \\
(\mathrm{HTLV}-1 / 2)\end{array}$ & 2007 & Puérperas del Estado de Minas Gerais & $\begin{array}{l}\text { Estudio transversal en } 55923 \\
\text { neonatos (programa tamizaje } \\
\text { neonatal) }\end{array}$ & 23 \\
\hline Inglaterra & $\begin{array}{c}0,04 \% \\
(\mathrm{HTLV}-1) \\
0,001 \\
(\mathrm{H} T L \mathrm{-}-2)\end{array}$ & $\begin{array}{l}1997- \\
1998\end{array}$ & $\begin{array}{l}\text { Gestantes de la región sur este de } \\
\text { Inglaterra }\end{array}$ & $\begin{array}{l}\text { Estudio transversal en } 126010 \\
\text { gestantes }\end{array}$ & 24 \\
\hline $\begin{array}{l}\text { Guyana } \\
\text { Francesa }\end{array}$ & $\begin{array}{c}4,4 \% \\
(H T L V-1)\end{array}$ & $\begin{array}{l}1991- \\
1993\end{array}$ & $\begin{array}{l}\text { Gestantes de Guyana Francesa, } \\
\text { departamento francés en Sudamérica }\end{array}$ & $\begin{array}{l}\text { Estudio retrospectivo en } 1727 \\
\text { gestantes }\end{array}$ & 25 \\
\hline Ghana & $\begin{array}{c}2,1 \% \\
(\mathrm{HTLV}-1)\end{array}$ & 2003 & $\begin{array}{l}\text { Gestantes de la ciudad de Accra, } \\
\text { Ghana }\end{array}$ & $\begin{array}{l}\text { Estudio transversal multicéntrico } \\
\text { en } 960 \text { gestantes }\end{array}$ & 26 \\
\hline Japón & $\begin{array}{c}5,6 \% \\
\text { (HTLV-1 entre } \\
1989 \text { y 1992) } \\
3,7 \% \\
\text { (HTLV-1 entre } \\
1997 \text { y } 2000)\end{array}$ & $\begin{array}{l}1989- \\
2000\end{array}$ & Isla de Ishigaki, Okinawa. & $\begin{array}{l}\text { Estudio transversal en } 3837 \\
\text { gestantes }\end{array}$ & 27 \\
\hline
\end{tabular}

de esta diferencia, es que en los estudios en donantes se excluye a las personas que presentan algún factor de riesgo; en cambio en los estudios en gestantes no se hace esta exclusión, lo cual hace que sea un grupo más heterogéneo que los donantes $y$, consecuentemente, más representativo de la población general. ${ }^{(1,11)}$ Este hecho refuerza la idea de que la prevalencia en gestantes es un buen indicador de endemicidad.

\section{PREVALENCIA ELEVADA EN GRUPOS EXPUESTOS A INFECCIONES DE TRANSMISIÓN SEXUAL (ITS)}

En la Tabla 3 se muestra la prevalencia en grupos de mayor exposición a ITS. Excepto los estudios en Ayacucho, en todos los demás la prevalencia es mayor al $1 \%$.

\section{INCREMENTO DE LA PREVALENCIA CON LA EDAD}

Varios estudios nacionales muestran que la prevalencia de HTLV-1 se incrementa a partir de los 20 años. Alarcón et al. encontraron que la prevalencia en gestantes fue de $0,6 \%$ en menores de 20 años, $1,6 \%$ de 20 a 30 años y $3,2 \%$ en mayores de 30 años. Esta tendencia se repite en el análisis de regresión ajustada, en el que el riesgo de las gestantes de 20 a 30 años y las mayores de 30 años fue 2,7 y 5,4 veces mayor que las menores de 20 años (8). Otro estudio realizado en el trapecio andino muestra la misma relación en pobladores asintomáticos, en la que la prevalencia de HTLV-1 en menores de 20 años fue de $11,1 \%$, mientras que en mayores de 40 años la prevalencia subió hasta $18,5 \%$. En este mismo estudio,

Tabla 3. Prevalencias de HTLV-1 en grupos de alto riesgo de transmisión de ITS en el Perú

\begin{tabular}{|c|c|c|c|}
\hline $\begin{array}{l}\text { Población } \\
\end{array}$ & Tamaño muestral & Prevalencia & Referencia \\
\hline Trabajadoras sexuales (Ayacucho) & 85 & $0 \%$ & 6 \\
\hline HSH (Ayacucho) & 74 & $0 \%$ & 6 \\
\hline Trabajadoras sexuales (Cusco) & 51 & $13,7 \%$ & 5 \\
\hline HSH o bisexuales (Cusco) & 48 & $6,2 \%$ & 5 \\
\hline Pacientes con ITS (Cusco) & 47 & $8,5 \%$ & 5 \\
\hline $\mathrm{HSH}$ (Pisco, Ica) & 54 & $1,9 \%$ & 10 \\
\hline Trabajadoras sexuales (Pisco, Ica) & 32 & $10,4 \%$ & 10 \\
\hline Trabajadoras sexuales (Callao) & 395 & $25,1 \%$ & 11 \\
\hline Trabajadoras sexuales (Iquitos) & 72 & $4,2 \%$ & 11 \\
\hline Usuarios de drogas no endovenosas (Lima) & 298 & $2,3 \%$ & 12 \\
\hline Trabajadoras sexuales (Lima) & 158 & $3,8 \%$ & 13 \\
\hline Varones en régimen privado de libertad (Lima) & 400 & $1,5 \%$ & 17 \\
\hline Pacientes varones con VIH & 111 & $18 \%$ & 29 \\
\hline
\end{tabular}

HSH: Hombres que tienen sexo con hombres 
se observó que en el grupo de trabajadoras sexuales la prevalencia fue de $0 \%$ en menores de 30 años y $28 \%$ en mayores de 30 años ${ }^{(5)}$. Estas observaciones también se han descrito en otras áreas endémicas.

El incremento de la prevalencia con la edad tiene varias explicaciones, como: la acumulación de seroconversión para HTLV-1 en el curso de la vida de los individuos estudiados, el retraso de la seroconversión a la infección adquirida tempranamente en la vida, el efecto edadcohorte debido a la disminución de la seroprevalencia de HTLV-1 en las últimas décadas y la edad de inicio de las relaciones sexuales (1). Esta última sumada al mayor número de parejas sexuales incrementa el riesgo de transmisión de HTLV-1 ${ }^{(1,30)}$, sobre todo de varón a mujer donde la transmisión de la infección se supone más eficiente ${ }^{(1)}$; sin embargo, un reciente estudio de cohorte revela que la trasmisión de varón a mujer no fue estadísticamente diferente a la de mujer a varón ${ }^{(31)}$.

\section{PREVALENCIA EN EMIGRANTES PERUANOS}

No hay estudios específicos de esta infección en población emigrante peruana, sin embargo, hay dos estudios publicados recientemente que investigan la procedencia de los casos prevalentes en países de baja endemicidad de infección por HTLV-1. Uno, realizado en España en 20366 gestantes, que encontró una prevalencia de HTLV de $0,064 \%$, de los cuales solo una gestante tuvo infección por HTLV-1, la cual provenía de Perú; el resto de casos eran de HTLV-2, todas provenientes de España y con fuerte relación con el uso de drogas inyectables ${ }^{(20)}$. Otro fue realizado en Italia en 393 inmigrantes recientes, 167 fueron trabajadoras sexuales (transexuales) $\mathrm{VIH}-1$ positivos y 226 fueron gestantes $\mathrm{VIH}-1$ negativas. Este estudio incluyó a 34 personas procedentes del Perú, $19 \mathrm{VIH}-1$ positivas y $15 \mathrm{VIH}$ negativas; entre las primeras, se encontró cinco personas HTLV-1 positivas (5/19) y entre las segundas, una persona infectada (1/15). Los autores también realizaron un análisis filogenético y concluyeron que los subtipos de HTLV-1 encontrados en inmigrantes están relacionados al virus prevalente en sus lugares de origen. No se encontró ningún caso de infección por HTLV-2 en inmigrantes procedentes del Perú (32).

\section{TRANSMISIÓN VERTICAL DE HTLV-I}

\section{TASA DE TRANSMISIÓN VERTICAL}

No se han realizado estudios específicos para determinar la tasa de transmisión vertical del HTLV-1 en el Perú. Sin embargo, hay algunos estudios que dan indicios de su magnitud. Montano et al. realizaron un estudio para determinar si la infección por HTLV-1 estaba asociada con retraso en el desarrollo neurológico en niños expuestos al HTLV-1 durante el periodo de lactancia; para este fin, entre 1996 y el 2000, identificaron 87 gestantes seropositivas para HTLV-1 de las cuales se incluyó a 67 madres infectadas y sus respectivos hijos, se encontró 12 casos de niños con infección por HTLV-1, que representa una tasa de transmisión de $18 \%{ }^{(15)}$, tasa similar a lo encontrado en varios estudios en Jamaica ${ }^{(33)}$, y a lo encontrado en Japón entre 1986 y 1991 antes de implementar políticas de acortamiento de la duración del periodo de lactancia en ese país ${ }^{(27)}$. Un reciente estudio de Gotuzzo y Col., que investigó la prevalencia de HTLV-1 en descendencia de madres peruanas infectadas por HTLV-1, encontró que el porcentaje de infectados en hijos de madres portadoras asintomáticas fue de $6 \%$, mientras que en hijos de madres con paraparesia espástica tropical fue $19 \%$ y en los hijos de madres con coinfección con estrongiloidiasis fue $31 \%{ }^{(34)}$.

Considerando estos estudios, podemos observar que la tasa de transmisión vertical de HTLV-1 en el país varía entre de 6 y $18 \%$ en el caso de madres portadoras asintomáticas y llega a alcanzar un $31 \%$ en el caso de madres con coinfección con estrongiloidiasis ${ }^{(15,34)}$. Estudios realizados en otros países endémicos han encontrado que la tasa de transmisión vertical de HTLV-1 en niños nacidos de madres seropositivas para HTLV-1 varía de 3,9 a 22\% dependiendo del estudio, los cuales principalmente han sido realizados en Jamaica y Japón ${ }^{(27,33-37)}$. En la Tabla 4 se muestran los detalles de los estudios.

\section{FACTORES DE RIESGO PARA TRANSMISIÓN VERTICAL}

La trasmisión vertical de HTLV-1 ocurre comúnmente a través de la lactancia materna, mientras que la infección transplacentaria e intraparto ha sido raramente reportada ${ }^{(1,14,34,38,39)}$. Los factores de riesgo que favorecerían la trasmisión vertical de HTLV-1 se pueden clasificar de la siguiente manera:

1) Factores asociados con la lactancia materna:

a) Duración del periodo de lactancia ${ }^{(27,34-41)}$.

b) Carga proviral en leche materna ${ }^{(37,41)}$.

2) Factores asociados con la infección por HTLV-1 en la madre

a) Condición clínica de la madre ${ }^{(34)}$.

b) Carga proviral en sangre periférica $(27,34,35,36)$.

c) Títulos elevados de anticuerpos anti- HTLV-1 en madres ${ }^{(27,33,36)}$

3) Otros factores asociados $(15,23,27,33,36)$. 
Tabla 4. Prevalencia de infección HTLV-1 por transmisión vertical

\begin{tabular}{|c|c|c|c|c|c|}
\hline País & $\begin{array}{c}\mathrm{N} .{ }^{\circ} \text { de gestantes sero- } \\
\text { positivas HTLV-1 }\end{array}$ & $\begin{array}{c}\mathrm{N} .^{\circ} \text { de niños nacidos } \\
\text { de madres seropositi- } \\
\text { vas de HTLV-1 }\end{array}$ & $\begin{array}{c}\text { N. }{ }^{\circ} \text { de niños infectados } \\
\text { con HTLV-1 hijos de ma- } \\
\text { dres seropositivas }\end{array}$ & $\begin{array}{c}\text { Tasa de transmisión } \\
\text { vertical }(\%)\end{array}$ & Referencia \\
\hline Guyana Francesa & 81 & 216 & 21 & 9,7 & 36 \\
\hline Jamaica & 150 & 154 & 28 & 18 & 33 \\
\hline Jamaica & 101 & 104 & 23 & 22 & 35 \\
\hline $\begin{array}{l}\text { Japón } \\
1986-1991 \\
1995-1999\end{array}$ & $\begin{array}{l}76 \\
36\end{array}$ & $\begin{array}{r}175 \\
76\end{array}$ & $\begin{array}{r}28 \\
3\end{array}$ & $\begin{array}{l}16 \\
3,9\end{array}$ & 27 \\
\hline Jamaica & 222 & 181 & 28 & $\begin{array}{c}18 \\
\text { (Incidencia estimada } \\
\text { acumulada) }\end{array}$ & 37 \\
\hline
\end{tabular}

\section{FACTORES ASOCIADOS CON LA LACTANCIA MATERNA}

\section{DURACIÓN DEL PERIODO DE LACTANCIA MATERNA}

Respecto a los factores asociados con la lactancia materna, Gotuzzo et al., en un estudio clínico sobre paraparesia espástica por HTLV-1, encontró que de 143 pacientes con dicha condición, $139(97,2 \%)$ refirieron haber recibido lactancia materna. De estos pacientes, 77 proporcionaron información acerca de la duración de la lactancia, entre estos últimos $72(93,5 \%)$ refirieron haber lactado más de 6 meses ${ }^{(40)}$. En otro estudio, el mismo autor observó que el riesgo de transmisión para los que lactaron de 6 a 12 meses fue 5,7 veces respecto a los que lactaron menos de 6 meses, 15,1 veces para los que lactaron de 12 a 24 meses y 18,8 veces para los que lactaron más de 24 meses ${ }^{(34)}$.

Recientemente Kendall et al. reportaron que entre niños peruanos infectados con HTLV-1, el promedio de lactancia fue mayor que el de niños no infectados hijos de madres seropositivas (22,4 meses y 15,5 meses respectivamente), sin embargo, en este estudio, no se menciona un punto de corte a partir del cual se podría recomendar evitar la lactancia materna ${ }^{(42)}$. En otro estudio nacional de Montano et al., realizado en 48 niños hijos de madres con HTLV-1, y que no se propuso estudiar la duración de la lactancia materna, no encontró diferencias significativas entre la media de la duración de la lactancia de los niños seropositivos (21,3 semanas) y los niños seronegativos (20,3 semanas) (15), es importante considerar que este resultado no es concluyente por la falta de potencia del estudio. Otro estudio colombiano no encuentra relación entre la duración de la lactancia materna con la trasmisión madre niño ${ }^{(43)}$. Además de estos hallazgos es importante señalar que la lactancia materna es una práctica extendida en el Perú. El 95\% de niños peruanos reciben lactancia materna y casi $50 \%$ de ellos continúa la lactancia durante su segundo año de vida ${ }^{(44)}$.
La importancia de la lactancia materna en la transmisión vertical del HTLV-1 también ha sido establecida en estudios en otras áreas endémicas. En Japón, entre el periodo de 1986-1991 la prevalencia de HTLV-1 en el grupo de no lactantes fue de $12,8 \%$, mientras que en los que recibieron lactancia materna este porcentaje fue de $18,6 \%$. Para el periodo entre 1995 a 1999, la prevalencia de HTLV-1 en no lactantes disminuyó hasta un $3,2 \%$, mientras que en el grupo de lactantes también se observó una franca disminución de la prevalencia llegando a un 4,4\%; esta disminución se atribuye a la disminución en el número de madres que practicaba la lactancia materna y a un acortamiento del periodo de la lactancia (27). Un hallazgo similar se ha observado en la Guyana Francesa, donde no se encontró ningún caso entre los hijos de madres seropositivas de HTLV-1 que no recibieron lactancia materna; mientras que en los que la recibieron, la prevalencia de infección de HTLV-1 fue de 10,6\%. Además, también se encontró que la tasa de infección disminuye con la menor duración del periodo de lactancia, siendo significativa si esta se reduce a menos de 6 meses ${ }^{(36)}$. Estos hallazgos son congruentes con lo encontrado por Hisada et al. en Jamaica, quien encontró asociación significativa entre la infección por HTLV-1 y la duración de la lactancia; sus resultados muestran que los que lactaron de 6 a 12 meses y los que lactaron más de 12 meses tuvieron respectivamente 4,4 y 10,2 veces el riesgo de infección respecto a los que lactaron menos de 6 meses ${ }^{(33)}$.

\section{CARGA PROVIRAL EN LECHE MATERNA}

Este factor de riesgo no ha sido estudiado en el Perú, sin embargo, se han realizado estudios en otros países endémicos. Un estudio prospectivo realizado en Jamaica en 101 parejas de madre-niño, encontró que la carga proviral en leche materna fue significativamente mayor en madres que trasmitieron HTLV-1 a sus niños que en aquellas que no ocurrió la transmisión, independientemente de la duración de lactancia materna. La incidencia de infección se incrementó con la carga proviral en leche materna; así, con una carga proviral 
de menos de $0,18 \%$ se tuvo una incidencia de 4,7/1000 personas-meses, mientras que con una carga proviral de más de 1,5\% la incidencia aumentó a 28,7/1000 personas-meses ${ }^{(35)}$. La mayor replicación del virus en la leche materna ha sido relacionada con la presencia de la proteína lactoferrina; en un estudio se ha encontrado que puede inducir la replicación de HTLV-1, activando la transcripción del promotor LTR HTLV-1, mecanismo que al parecer es específico para el HTLV-1, pues no se ha observado lo mismo para el VIH ${ }^{(45)}$.

\section{FACTORES ASOCIADOS A LA INFECCIÓN POR HTLV-1 EN LA MADRE}

\section{CONDICIÓN CLÍNICA DE LA MADRE}

Gotuzzo et al. estudiaron la asociación entre algunas condiciones clínicas de la madre y la tasa de infección; encontró que los hijos de madre seropositivas y con infección con estrongiloidiasis tuvieron 11,5 veces más riesgo de infección que los hijos de madres seropositivas asintomáticas y que los hijos de madre con paraparesia espástica tropical tuvieron 8,3 veces más riesgo de infección que los hijos de madres asintomáticas ${ }^{(34)}$. No hemos encontrado otros estudios que exploren esta asociación.

\section{CARGA PROVIRAL EN SANGRE PERIFÉRICA}

Este factor de riesgo no ha sido estudiado en nuestro medio, sin embargo, varios estudios en países endémicos han encontrado asociación entre el incremento del riesgo de transmisión vertical de HTLV-1 y la carga proviral materna en sangre periférica ${ }^{(27,33,35,36)}$. Un estudio realizado en la Guyana Francesa, encontró que una carga proviral de $\geq 500$ copias por $0,7 \mu \mathrm{g}$ de DNA de células mononucleares de sangre periférica aumenta en 8,1 veces el riesgo de transmisión de HTLV-1, independientemente de la duración de la lactancia materna y del sexo del niño. (36) Otro estudio realizado en Jamaica, muestra que la carga proviral (expresada en logaritmo base 10 de las copias $/ 10^{5}$ células) aumenta el riesgo de trasmisión vertical, así, una carga de menos de 2,0 $\log _{10}$ copias $/ 10^{5}$ células o $0,1 \%$, produce un riesgo insignificante, en cambio el riesgo aumenta exponencialmente cuando la carga es $\geq$ $3,0 \log _{10}$ copias $/ 10^{5}$ células o $1 \%{ }^{(33)}$.

\section{TITTULOS ELEVADOS DEANTICUERPOS ANTI HTLV-1 EN MADRES}

Similarmente a lo que ocurre con la carga proviral en leche materna, el riesgo de transmisión es insignificante cuando la madre tiene títulos de anticuerpo HTLV-1 de < $2,0 \log _{10}$, pero el riesgo se incrementa exponencialmente cuando el título es $\geq 2,0 \log _{10}$. Los niveles de anticuerpos maternos de la transferencia pasiva disminuyen a los 11 meses en promedio, de modo que la lactancia materna de más de 12 meses produce incremento en el riesgo de transmisión a través de la leche materna. Esto se confirma en el estudio de Hisada et al. (33), que encontró que cada cuartil de incremento en los títulos de anticuerpos maternos estuvo asociado con un retraso significativo en la infección de HTLV-1 entre niños que lactaron por menos de 12 meses, pero no entre los niños que lactaron por más de 12 meses. Estos hallazgos apoyan la hipótesis de que la exposición a provirus HTLV-1 tiene menos probabilidades de producir infección en el niño durante el tiempo en que hay transferencia pasiva de los anticuerpos maternos ${ }^{(27,33,36)}$.

\section{OTROS FACTORES ASOCIADOS}

En el país no se han publicado estudios diseñados para establecer otros factores relacionados con la transmisión vertical. Sin embargo, Montano et al. (15) encontraron que la tasa de seropositividad en hijos de madres portadoras de HTLV-1 fue mayor en varones que en mujeres, también encontraron que tres de seis niños con desnutrición crónica tuvieron infección por HTLV-1 ${ }^{(15)}$. Con relación al sexo, en Jamaica se han observado hechos contradictorios; en un estudio se encontró una mayor incidencia entre niñas, con un Odds ratio (OR) ajustado para títulos de anticuerpo anti HTLV-1 de 3,6 y OR ajustado para carga proviral materna de 4,1 ${ }^{(35)}$; en otros estudios se encontró que el riesgo de trasmisión vertical de HTLV-1 fue similar en niños y niñas ${ }^{(34,36,43)}$. Un estudio realizado en el Japón tampoco encontró diferencias por sexo ${ }^{(27)}$.

\section{CONCLUSIONES Y RECOMENDACIONES}

Como hemos podido observar en esta revisión, la infección por HTLV-1 tiene un comportamiento endémico en el Perú, favorecido por condiciones que facilitan su transmisión. Estas condiciones pueden ser divididas en factores biológicos y epidemiológicos. Entre los primeros, hay que destacar las características en la composición de la leche materna que favorece la replicación del virus (35,45); entre los epidemiológicos destacan la costumbre ampliamente difundida de la lactancia materna prolongada ${ }^{(37)}$, la elevada prevalencia en gestantes ${ }^{(5,8)}$ y el incremento de la prevalencia con la edad ${ }^{(5,6,8)}$.

La tasa de transmisión vertical en el Perú se encuentra entre $6 \%{ }^{(34)}$ y $18 \%{ }^{(15)}$ si se considera solo a la población asintomática, pudiendo llegar hasta $31 \%$ en población sintomática ${ }^{(34)}$. Esta tasa es semejante a la encontrada en otros países endémicos, sin embargo, es necesario hacer estudios más específicos para precisar este riesgo en nuestro medio. En este mecanismo de transmisión, 
los estudios sugieren que la duración de la lactancia materna cumple una función importante. Un estudio nacional y en otros países endémicos (Jamaica, Japón) indica que la lactancia materna de más de 6 meses es un factor de riesgo importante para la transmisión vertical de HTLV-1.

Aunque los datos no son concluyentes, por la poca potencia de los estudios realizados, existen características de los niños expuestos a la infección por HTLV-1 relacionadas con la transmisión vertical que deberían estudiarse más, como el sexo, edad y estado nutricional.

Finalmente, en función de estas evidencias, es importante establecer algunas medidas de control y prevención en forma urgente. Entre ellas, es importante considerar las siguientes:

- Implementar el tamizaje de HTLV-1 durante el control prenatal de las gestantes en áreas endémicas;

- Aconsejar la reducción de la duración de la lactancia materna en gestantes infectadas con HTLV-1, debidamente confirmadas. De acuerdo con las orientaciones actuales, esta recomendación no afectaría la norma nacional de mantener la lactancia materna exclusiva hasta los seis meses.

\section{Conflictos de Interés}

El autor declara no tener conflictos de interés.

\section{Descargo de Resposabilidad}

Las opiniones y afirmaciones contenidas aqui son propias de los autores y no deben interpretarse como posición oficial o que reflejan la opinión del Departamento de la Marina o del Servicio Naval de los Estados Unidos.

\section{REFERENCIAS BIBLIOGRÁFICAS}

1. Proietti F, Carneiro-Proietti A, Catalan B, Murphy E. Global epidemiology of HTLV-1 infection and associated diseases. Oncogene 2005; 24:6058-6068.

2. Carneiro-Proetti A, Catalán B, Proeitti F, GIPH. Human T Cell Lymphotropic Viruses (HTLV-1/II) in South America:Should It Be a Public Health Concern?. J Biorned Sci 2002; 9:587-595.

3. Gotuzzo E, Arango C, de Queiros-Campos A, Isturiz R. Human T-cell lymphotropic virus-I in Latin America. Infect Dis Clin North Am 2000; 14:211-39.

4. Hlela C, Shepperd S, Khumalo N, Taylor G. The Prevalence of Human T-Cell Lymphotropic Virus Type 1 in the General Population is Unknown. AIDS Rev 2009; 11:205-14.

5. Zurita S, Costa C, Watts D, Indacochea S, Campos P, Sanchez J, et al. Prevalence of human retroviral infection in Quillabamba and Cuzco, Peru: a new endemic area for human T-cell lymphotropic virus type I. Am J Trop Med Hyg 1997; 56:561-5.

6. Juscamaita Z, Torrealva M, Cairampoma R, Gotuzzo E. Seroprevalencia del Virus Linfotropo $T$ humano tipo 1 (HTLV-1) en gestantes y grupos de elevada prevalencia para enfermedades de transmisión sexual de Ayacucho, Perú. Rev Peru Med Exp Salud Pública 2004; 21(4): 269-272.

7. Gotuzzo E, Sánchez J, Escamilla J, Carrillo C, Phillips IA,Moreyra L, et al. Human T-cell lymphotropic virus type I infection among female sex workers in Peru. J Infect Dis 1994; 169:54-59.

8. Alarcón J, Friedman H, Montano S, Zunt JR, Holmes KK, Quinnan G. High endemicity of Human T-cell Lymphotropic Virus Type 1 among pregnant women in Perú. J Acquir Inmune Defic Syndr 2006. 15;42(5): 604-609.

9. Sanchez C, Gotuzzo E, Vandamme A, Maldonado Y. Seroprevalence and risk factors for human T-cell lymphotropic virus (HTLV 1) infection among ethnically and geographically diverse Peruvian women. Int $\mathrm{J}$ Infect Dis 2003; 7(2):132-137.

10. Garrido P, Anicama R, Gotuzzo E, Chauca G, Watts D. HTLV-1 en población de alto riesgo sexual de Pisco- Ica, Perú. Rev Med Hered 1997; 8(3): 104-107.

11. Wignall F, Hyams K, Phillips I, Escamilla J, Tejada A, Li $\mathbf{O}$,et al. Sexual transmission of human T-lymphotropic type I in peruvian prostitutes. J Med Virol 1992; 38: 44-48.

12. Muñoz D, Trujillo L, Gotuzzo E, Nizama M, Watts D. Prácticas sexuales de riesgo y seroprevalencia de infección por VIH-1. HTLV-1, sífilis y hepatitis $B$ en varones drogadictos no endovenosos de Lima. Rev Med Hered 1997; 8:92-104.

13. Trujillo L, Muñoz D, Gotuzzo E, Nizama M, Watts D. Prácticas sexuales y seroprevalencia de infección por VIH, HTLV-1 sífilis en meretrices clandestinas de Lima. Rev Med Hered 1996; 7(4): 162-171.

14. Gotuzzo E, Verdonck K, González E, Cabada M. Virus Linfotrópico Humano de células T tipo 1 (HTLV-1): una infección endémica en el Perú. Rev Perú Med Exp Salud Publica 2004; 21(4):253-260.

15. Montano S, Zunt J, Rodriguez L, Quispe I, Rodriguez C, Altamirano J, et al. Human T Cell Lymphotropic Virus Type 1 Infection and Early Neurologic Development: A Pilot Study of 48 Children. Clinical Infectious Diseases 2004; 39(1): 1079-82.

16. Quispe N, Feria E, Santos E, Caterino A. Confirming the presence of HTLV-1 infection and the absence of HTLV-2 in blood donors from Arequipa, Peru. Rev. Inst. Med. trop. S. Paulo 2009;51(1): 25-29.

17. Garcia J, Jimenez G. Estudio comparativo sobre la seroprevalencia de HTLV-1 en una población de adultos en régimen privado de libertad y una población urbano marginal de Lima. 2002. Tesis para optar titulo de especialidad en dermatología. UNMSM.

18. Gotuzzo E, Yamamoto V, Kanna M, Chauca G, Watts D. Human T-cell lymphotropic virus type I infection among Japanese immigrants in Peru. Int J Infec Dis 1996; 1(2):7577.

19. Trenchi A, Gastaldello R, Balangero M, Irizar M, Cudola A , Gallego S. Retrospective Study of the Prevalence of Human T-Cell Lymphotropic Virus-Type 1/2, HIV, and 
HBV in Pregnant Women in Argentina. Journal of Medical Virology 2007; 79:1974-1978.

20. Machuca A, Tuset C, Soriano V, Caballero E, Aguilera A, Ortiz de Lejarazu R. Prevalence of HTLV infection in pregnant women in Spain. Sex Transm Inf 2000; 76:366370.

21. Ribeiro R, Ferreira D, Dutra J, Fernandes C. Prevalence of human T-cell lymphotropic virus (HTLV-1/2) infection among puerperae in Cuiabá, Mato Grosso, 2006. Revista da Sociedad Brasileira de Medicina Tropical 2009; 42(1):28-32.

22. Figueiró E, Antunes A, de Almeida F, Gonçalves de Souza S, Botelho C, Duarte G. T-cell leukemia virus infection in pregnant women in a Central-Western state of Brazil. Rev Bras Ginecol Obstet 2005; 27(12): 719-25.

23. Ribeiro M, Proietti F, Martins M, Januário J, Puglia Ladeira R, Oliveira $\mathbf{M}$ et al. Geographic distribution of human T-lymphotropic virus types 1 and 2 among mothers of newborns tested during neonatal screening, Minas Gerais, Brazil. Rev Panam Salud Publica 2010; 27(5):330-7.

24. Ades A, Parker S, Walker J, Edginton E, Taylor G, Weber J. Human $\mathrm{T}$ cell leukaemia/lymphoma virus infection in pregnant women in the United Kingdom: population study. BMJ 2000; 320:1497-1501

25. Carles G, Tortevoye P, Tuppin P, Ureta A. Infection par le rétrovirus HTLV-1 et grossesse. J Gynecol Obstet Biol Reprod 2004; 33 (1): 14-20.

26. Armah H, Narter E, Adjei A, Asomaning K, Gyasi R, Tettey $\mathrm{Y}$. Seroprevalence of human T-cell lymphotropic virus type I among pregnant women in Accra, Ghana. Journal of Medical Microbiology 2006; 55:765-770.

27. Kashiwagi K, Furusyo N, Nakashima H, Kubo N, Kinukawa N, Kashiwagi S, et al. A decrease in motherto-child transmission of Human T Lymphotropic virus Type I (HTLV-1) in Okinawa, Japan. Am. J. Trop. Med. Hyg 2004; 70(2):158-163.

28. Taylor G, Bodeus M, Courtois F, Pauli G, Del Mistro A, Machuca A, et al. The seroepidemiology of human T-lymphotropic viruses: types I and II in Europe: a prospective study of pregnant womenJ. Acq. Immun. Def. Synd 2005;38, 104-109.

29. Gotuzzo E, Escamilla J, Phillips IA, Sanchez J, Wignall FS, Antigoni J. The Impact of Human T-Lymphotrophic Virus Type I/II Infection on the Prognosis of Sexually Acquired Cases of Acquired Immunodeficiency Syndrome. Arch Intern Med 1992; 152: 1429-1432.

30. Goncalves D, Proietti F, Ramos J, Grossi M, Pinheiro S, Guedes A, et al. Epidemiology, Treatment, and Prevention of Human T-Cell Leukemia Virus Type 1-Associated Diseases. Clin Microb review 2010; 23(3): 577-589.

31. Roucoux D, Wang B, Smith D, Nass C, Smith J, Hutching S, et al. A Prospective Study of Sexual Transmission of Human T Lymphotropic Virus (HTLV)-I and HTLV-II. JID 2005:191: 1490-7.

32. Zehender G, Colasante Ch, De Maddalena Ch, Bernini F, Savasi V, Persico T et al. High Prevalence of Human T-Lymphotropic Virus Type 1 (HTLV-1) in Immigrant Maleto-Female Transsexual Sex Workers With HIV-1 Infection. Journal of Medical Virology 2004; 74:207-215.

33. Hisada H, Maloney E, Sawada T, Miley W, Palmer P, Hanchard B, et al. Virus Markers Associated with Vertical Transmission of Human T Lymphotropic Virus
Type 1 in Jamaica. Clinical Infectious Diseases 2002; $34: 1551-7$

34. Gotuzzo E, Moody J, Verdonck K, Cabada M, González $\mathbf{M}$, Van Dooren S, et al. Frequent HTLV-1 infection in the offspring of Peruvian women with HTLV-1-associated myelopathy/tropical spastic paraparesis or strongyloidiasis. Rev Panam Salud Publica/Pan Am J Public Health 2007; 22(4): 223-230.

35. Li H, Biggar R, Miley W, Maloney E, Cranston B, Hanchard B, et al. Provirus Load in Breast Milk and Risk of Mother-to-Child Transmission of Human T Lymphotropic Virus Type I. The Journal of Infectious Diseases 2004; 190:1275-8.

36. Ureta A, Angelin C, Tortevoye P, Murphy E, Lepere. J, Buigues. R, et al. Mother-to-child transmission of human T-cell-leukemia/lymphoma virus type I: implication of high antiviral antibody titer and high proviral load in carrier mothers. Int. J. Cancer 1999; 82, 832-836.

37. Wiktor S, Pate E, Rosenberg P, Barnett M, Palmer P, Medeiros D, et al. Mother-to-child transmission of human T-cell lymphotropic virus type I associated with prolonged breast-feeding. J Hum Virol. 1997;1(1):37-44.

38. Fujino T, Nagata Y. HTLV-1 transmission from mother to child. J Reprod Immunol. 2000;47(2):197-206.

39. Bittencourt A, Sabino E, Costa M, Pedroso C, Moreira L. No evidence of vertical transmission of HTLV-1 in bottle-fed children. Rev Inst Med Trop Sao Paulo 2002;44(2):63-5.

40. Gotuzzo E, Cabrera J. Clinical Characteristics of Patients in Peru with Human T Cell Lymphotropic Virus Type 1-Associated Tropical Spastic Paraparesis. CID 2004;39:939-944.

41. Furnia A, Lal R, Maloney E, Wiktor E, Pate E, Rudolph D, et al. Estimating the Time of HTLV-1 Infection Following Mother-to-Child Transmission in a Breast-Feeding Population in Jamaica. Journal of Medical Virology 1999; 59:541-546.

42. Kendall E, Gonzales E, Espinoza I, Tipismana M, Verdonck K, Clark D, et al. Early Neurologic abnormalities associated with Human T - Cell Lymphotropic virus type 1 Infection in a cohort of Peruvian children. J pediatr 2009; 155:700-6.

43. Arango C, Rugeles MT, Concha M, Borrero I I, Lai H, Lai S, et al. Risk factors for HTLV-I mother to child transmission: influence of genetic markers. Braz J Infect Dis 1998; 2(3):135-42.

44. Rice S, Coombs D, Fish L, Leeper J. Breastfeeding and contraception in Peru. J Health Popul Nutr. 2002;20(1):51-8.

45. Moriuchi M, Moriuchi H. A Milk Protein Lactoferrin Enhances Human $T$ Cell Leukemia Virus Type I and Suppresses HIV-1 Infection. The Journal of Immunology 2001;166: 4231-4236.

Correspondencia: Jorge Alarcón Villaverde.

Instituto de Medicina Tropical "Daniel A. Carrión"

Facultad de Medicina, UNMSM.

Jr. José Santos Chocano 199. 4to. piso.

Urb. San Joaquín - Bellavista

Callao 2, Perú.

Correo electrónico: jalarconv@epiredperu.net 